\title{
Crown ether functionalization of a porphyrin-based "molecular square": induction of fluorescence sensitivity to alkali metal cations
}

\author{
Seung Hyun Chang ${ }^{a}{ }^{*}$, Kwang-Bo Chung ${ }^{b}$, Rovert V. Slone ${ }^{c}$, Joseph T. Hupp ${ }^{c}$ \\ ${ }^{a}$ Department of Chemistry, Taegu University, Taegu 713-714, South Korea \\ ${ }^{\mathrm{b}}$ Department of Chemical Engineering, Hanseo University, Seosan 356-820, South Korea \\ ${ }^{\mathrm{c}}$ Department of Chemistry, Northwestern University, Evanston, IL 60208, USA
}

\begin{abstract}
A porphyrin-based "molecular square" (1), prepared by reaction of a dipyridylporphyrin species with $\mathrm{Re}(\mathrm{CO})_{5} \mathrm{Cl}$ and subsequently with $\mathrm{Zn}^{\mathrm{II}}$ acetate, was functionalized with 2-(methylene-15-crown-5-ether)-nicotinoyl ester (2). Functionalization was achieved by axially ligating each of the four available $\mathrm{Zn}^{\mathrm{II}}$ sites within the porphyrins. (2) was synthesized by reaction of 2-(hydroxymethyl)-15-crown-5-ether and nicotinoyl chloride in $\mathrm{CH}_{2} \mathrm{Cl}_{2}$. Functionalization renders the square's fluorescence emission intensity responsive to added $\mathrm{Na}^{+}$and, to a lesser extent, $\mathrm{K}^{+}$. (C) 2001 Published by Elsevier Science B.V.
\end{abstract}

Keywords: Porphyrin square; Methylene crown; Luminescence; Binding constant

\section{Introduction}

The advantages of molecular fluorescence or luminescence for sensing have been summarized [1] and many of the structural features which control fluorescence efficiency have been delineated [2,3]. Rigid macrocycles (molecular squares) based on cis bridging ligation of transition metals represent an unusual class of compounds having significant promise in solution-phase host-guest, inclusion and molecular recognition chemistry [4-7]. The 50 or so available squares have been constructed from platinum, palladium, nickel, tungsten, and rhenium precursors and have been assembled in both homometallic and heterometallic forms [4-7]. In addition, selected neutral squares have been evaluated in the solid state as thin films. In film form, the compounds exhibit exceptional nanometer-scale porosity, enormous internal surface areas, and useful molecular binding properties - where binding can be followed, for example, by quartz crystal microgravimetry [7].

In solution, on the other hand, host-guest binding is typically monitored via NMR spectroscopy. In a few cases, binding has also been monitored via changes in host luminescence.

In this paper, we report on (a) the reversible functionalization of a porphyrin-based molecular square (1) with a known cation receptor (2-(methylene-15-crown-5-ether)nicotinoyl ester (2)), and (b) the use of the functionalized

* Corresponding author. square as a solution-phase sensing assembly (fluorescent assembly) for alkali metal ions.

\section{Experimental}

As described previously [8], the free base form of the tetraporphyrin square was obtained in high yield by stoichiometrically combining 2,8,12,18-tetrabutyl-3,7,13,17tetramethyl-5,15-bis-(4-pyridyl)porphyrin and $\operatorname{Re}(\mathrm{CO})_{5} \mathrm{Cl}$ in $100 \mathrm{ml}$ of freshly distilled 4:1 THF-toluene as solvent, and then heating at reflux for $48 \mathrm{~h}$. The analogous tetra-zinc metallated square was obtained quantitatively by treating the tetraporphyrin square with zinc acetate in methanol $+\mathrm{CH}_{2} \mathrm{Cl}_{2}$. (2) was obtained from 2-(hydroxymethyl)-15-crown-5-ether and nicotinoyl chloride. Absorption and emission spectra were recorded by using a Cary 3 UV-VIS absorption spectrophotometer and an SPEX Flouromax spectrofluorimeter.

\section{Results and discussion}

Fig. 1 illustrates the structure of the tetraporphyrin square. A key feature is the use of tricarbonylrhenium chloro fragments as corners. Despite the fact that rhenium is a third-row transition metal, heavy-metal quenching of the porphyrin-based luminescence appears to be absent. Indeed, the room temperature luminescence lifetime of the photo- 


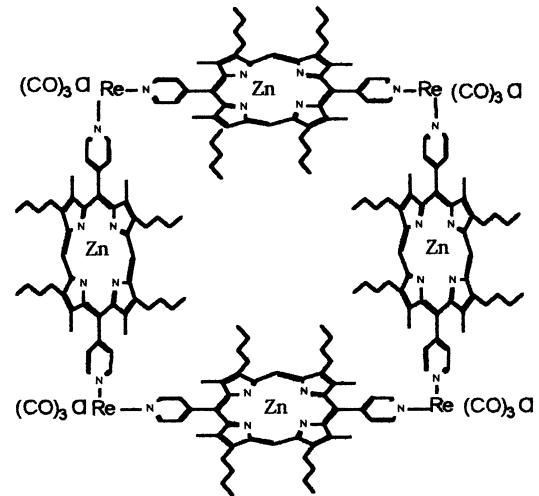

(1)

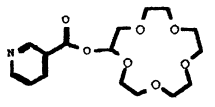

(2)
Fig. 1. Structure of porphyrin square (1) and methylene crown ether (2).

excited square assembly is nearly identical to that of the free porphyrin ligand [8]. Interestingly, closely related porphyrin squares featuring $\mathrm{Pt}(\mathrm{II})$ or $\mathrm{Pd}(\mathrm{II})$ corners are nonemissive $[9,10]$, apparently because of efficient redox quenching by the corner entities [7] (Fig. 2).

As indicated in Fig. 3, emission from the zinc metallated square decreases upon addition of the pyridine-functionalized crown ether in $\mathrm{CH}_{2} \mathrm{Cl}_{2}$ as solvent. While the guest lacks obvious energy-transfer or electron-transfer quenching capabilities, a ligation-induced decrease in host luminescence intensity is not unexpected [11,12]. An observed $5 \mathrm{~nm}$ limiting red shift in the emission spectrum of (1) supports the contention that (2) interacts with the square via axial ligation. From additional measurements at lower host concentrations, the host (1)-guest (2) binding constant is $1.1 \times 10^{7} \mathrm{M}^{-1}$. Further insight into the binding is provided by electronic absorption measurements. Host-guest mixtures in the ratio of 1:4 exhibit a quantitative shift of host $\mathrm{Q}$ bands to longer wavelength at micromolar host concentrations. The absorption studies are consistent, therefore, with a binding geometry which entails pyridine-crown ligation of all available $\mathrm{Zn}$ sites [13-15]. As shown in Fig. 4, the emission is enhanced by NaSCN addition. The emission

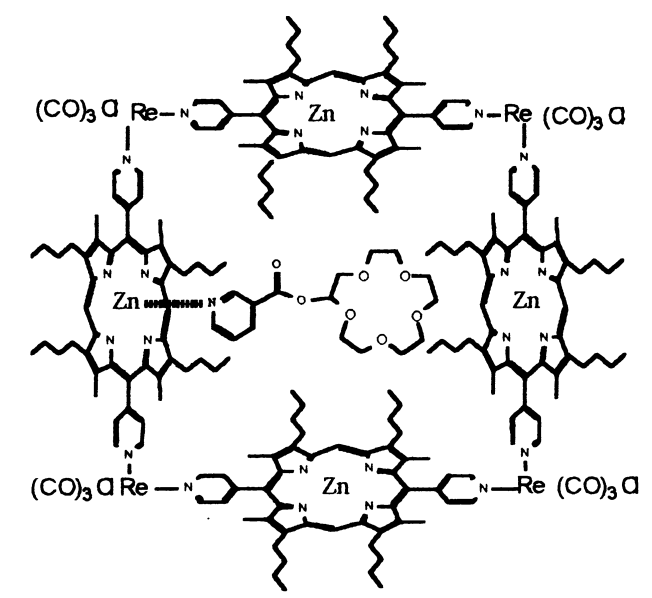

Fig. 2. Porphyrin square with one methylene crown ether moiety.

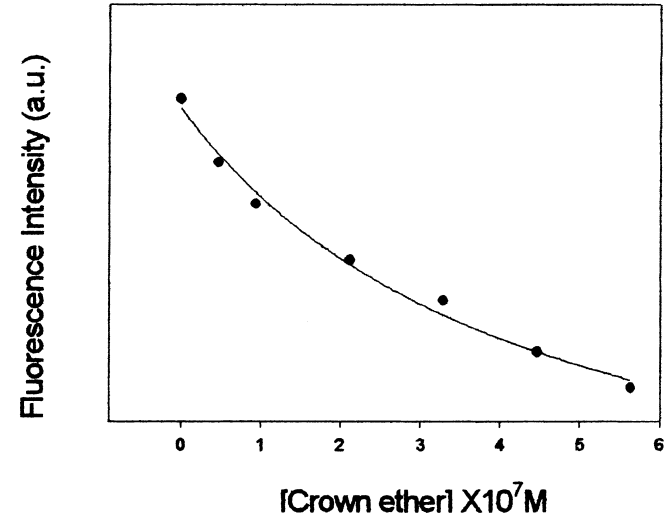

Fig. 3. Porphyrin square fluorescence emission intensity vs. methylene crown ether concentration.

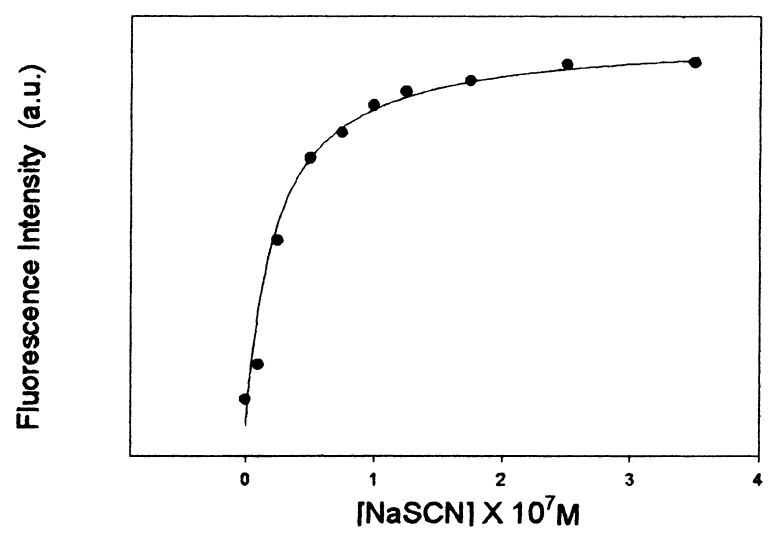

Fig. 4. Fluorescence emission from the porphyrin square-crown ether mixture as a function of $[\mathrm{NaSCN}]$.

energy, however, is unchanged. A control experiment, where the receptor ligand is omitted, yields no change in emission intensity with added NaSCN. We ascribe the effect, therefore, to a subtle tuning of $\mathrm{Zn}-\mathrm{N}$ interactions brought about by $\mathrm{Na}^{+}$binding within the crown ether. From Fig. 4 , the apparent binding constant is $4 \times 10^{7} \mathrm{M}^{-1}$. Because the measurements were made at concentrations near the host (1)-guest (2) dissociation limit, it is conceivable that the true $\mathrm{Na}^{+}$binding constant is higher. A similar experiment with KSCN yields a smaller intensity enhancement and a binding constant of ca. $8 \times 10^{6} \mathrm{M}^{-1}$.

\section{Acknowledgements}

This work was supported in part by the Taegu University Research Grant, 1999, and by the US National Science Foundation (CHE-9810483).

\section{References}

[1] A.J. Bryan, A.P. de Silva, S.A. de Silva, R.A.D.D. Rupasinghe, K.R.A.S. Sandanayake, Biosensors 4 (1989) 169. 
[2] J.R. Lakowicz, Principles of Fluorescence Spectroscopy, Plenum Press, New York, 1983.

[3] Y. Takeda, Top. Curr. Chem. 1 (1984) 121.

[4] M. Fujita, J. Yakazi, K. Ogura, J. Am. Chem. Soc. 115 (1993) 1574.

[5] M. Fujita, Chem. Soc. Rev. 27 (1998) 417.

[6] C.A. Hunter, Angew. Chem. Int. Ed. Engl. 10 (1995) 1079 and references therein.

[7] R.V. Slone, J.T. Hupp, S. Bélanger, I.A. Guzei, A.L. Rheingold, Coord. Chem. Rev. 171 (1998) 221.

[8] R.V. Slone, J.T. Hupp, Inorg. Chem. 36 (1997) 5422.

[9] J. Fan, J.A. Whiteford, B. Olenyuk, M.D. Levin, P.J. Stang, E.B. Fleischer, J. Am. Chem. Soc. 121 (1999) 2742.
[10] J.-M. Lehn, C.M. Drain, J. Chem. Soc., Chem. Commun. 2313 (1994).

[11] R.V. Slone, D.I. Yoon, R.M. Calhoun, J.T. Hupp, J. Am. Chem. Soc. 117 (1995) 11813.

[12] D.G. Whitten, I.G. Lopp, P.D. Wildes, J. Am. Chem. Soc. 90 (1968) 7196.

[13] S. Anderson, H.L. Anderson, J.K.M. Sanders, Acc. Chem. Res. 26 (1993) 496.

[14] H.L. Anderson, C.A. Hunter, N. Meah, J.K.M. Sanders, J. Am. Chem. Soc. 112 (1990) 5780.

[15] S. Bélanger, M.H. Keefe, J. Welch, J.T. Hupp, Coord. Chem. Rev. 192 (1999) 29. 